\title{
Brief Communication: Low-cost, on-demand aerial photogrammetry for glaciological measurement
}

\author{
K. Whitehead, B. J. Moorman, and C. H. Hugenholtz \\ Department of Geography, University of Calgary, Calgary, Alberta, Canada
}

Correspondence to: K. Whitehead (kwhitehe@ucalgary.ca)

Received: 22 May 2013 - Published in The Cryosphere Discuss.: 25 June 2013

Revised: 26 November 2013 - Accepted: 28 November 2013 - Published: 13 December 2013

\begin{abstract}
Remotely sensed glaciological measurements can be expensive, often involving a trade-off between resolution, scale, and frequency. We report on a case study in which two low-cost techniques were used to generate digital elevation models and orthomosaics of an Arctic glacier in consecutive ablation seasons. In the first aerial survey we used an unmanned aerial vehicle and acquired images autonomously. The following year we took advantage of the helicopter used for site access, and were able to acquire images manually, for little additional helicopter time. We present a preliminary assessment of accuracy and apply these data to measure glacier thinning and motion.
\end{abstract}

\section{Introduction}

Remote sensing technology to monitor the cryosphere has expanded over the past few decades in several key areas, as evidenced by advances in InSAR (e.g. Quincey and Luckman, 2009), LiDAR (e.g. Arnold et al., 2006), and the provision of publicly available software and data via web portals. However, fundamental challenges remain in terms of the availability of data, spatial resolution, and temporal baselines between data acquisitions. Due to a number of confounding factors researchers are often forced to compromise between what is desirable for their project and what is actually possible. In an attempt to address this issue we present here a case study showing how remote sensing data can be acquired from low-cost, on-demand aerial surveys, in order to measure glacier surface change and dynamics in 3-D.

Typically, remote sensing data used in glaciology are acquired from fixed-wing aircraft, helicopters, or satellites, with researchers often having to rely on imagery gathered for other purposes, such as government map updates (e.g. Wainstein et al., 2008). Satellite imagery may be appropriate for some types of measurements, but it may be subject to limitations such as cost, weather conditions, and resolution. Georeferencing may also pose significant challenges in some glaciated areas, where stable reference points are unavailable. While no single technique can overcome all the foregoing issues, significant advances in digital photogrammetry and autonomous aerial platforms provide a number of new options to researchers (e.g. d'Oleire-Oltmanns et al., 2012; Hugenholtz et al., 2012, 2013).

A key advantage of photogrammetry is that it extracts topography from overlapping images, which allows spatiotemporal changes of the surface to be measured in 3-D. Software advances have driven the initial costs down, while also offering more flexibility in the type of data processed. The Inpho package used in this study is designed for highthroughput aerial surveys. As such it does not fall into the category of budget software. However, much of the functionality of this software can be duplicated by freely available packages such as Bundler (e.g. James and Robson, 2012; Westoby et al., 2012), and Microsoft's Photosynth (e.g. Fonstad et al., 2013), complemented by point cloud editing software such as Meshlab (e.g. Fonstad et al., 2013).

A parallel development is the advent of lightweight, low-cost unmanned aerial vehicles (UAVs). These resemble radio-controlled hobby aircraft, but fly autonomously according to a pre-programmed flight path. Flight planning software establishes the optimal image coverage, so that the area of interest is fully covered by multiple stereo image combinations. The aircraft then flies the predetermined course, using an onboard autopilot to guide the flight and image acquisition. Typically, the autopilot receives inputs from 
an integrated global navigation satellite system (GNSS) and inertial measurement unit (IMU), which provides $X, Y$, and $Z$ positions to within $10 \mathrm{~m}$, and values for aircraft roll, pitch, and yaw to better than $2^{\circ}$. On completion of the flight, a log file is normally downloaded from the aircraft. This file gives provisional $X, Y$, and $Z$ positions, as well as values for aircraft roll, pitch, and yaw, which are logged several times a second. This information can be used as an input to a photogrammetric block-adjustment process.

Our primary goal in this paper is to demonstrate the applicability and accuracy of UAV-based remote sensing data for measuring surface motion and elevation changes of an Arctic glacier. The small fixed-wing UAV used in this investigation is shown in Fig. 1. Originally, we intended to present data from two consecutive UAV surveys of the same glacier in 2010 and 2011; however, due to technical issues we were unable to perform the 2011 survey with the UAV. Instead, we were forced to adapt the project and improvise, which meant incorporating imagery from a piloted helicopter. Through processing we generated a digital elevation model (DEM) and an orthomosaic with accuracies comparable to those obtained from the previous year's UAV survey. It is recognised that helicopter time is expensive, with typical rates being in the region of $\$ 2000$ per hour. However, many glaciological studies require the use of helicopters for access purposes. The survey described in this study took less than $15 \mathrm{~min}$ of additional helicopter time to execute, making it considerably less expensive than custom aerial photo or satellite image acquisitions.

\section{Study site and methodology}

The case study was undertaken at Fountain Glacier, which is a small Arctic polythermal glacier situated on southern Bylot Island (Fig. 1). Fountain Glacier is approximately $16 \mathrm{~km}$ long and is $1.2 \mathrm{~km}$ wide close to the terminus. According to Moorman (2003) the glacier terminus first started to show signs of retreat in 1996. Wainstein et al. (2008) also showed that the terminus region thinned by approximately $25 \mathrm{~m}$ between 1982 and 2007. This part of the glacier is generally slow-moving and terminates in a vertical cliff, which is $35 \mathrm{~m}$ high in places (Wainstein et al., 2010). It is believed that close to this calving face, the glacier is frozen to its bed, resulting in very slow down-glacier motion rates of between 2 and $5 \mathrm{ma}^{-1}$ (Whitehead et al., 2010). The terminus region is dominated on the south side by a deeply incised supraglacial stream which acts as the major drainage channel for meltwater from the lower glacier.

\subsection{UAV survey}

The first of two planned UAV surveys of Fountain Glacier's terminus was carried out on 1 July 2010. The aircraft used was an Outlander UAV (Fig. 1), which carried a Panasonic
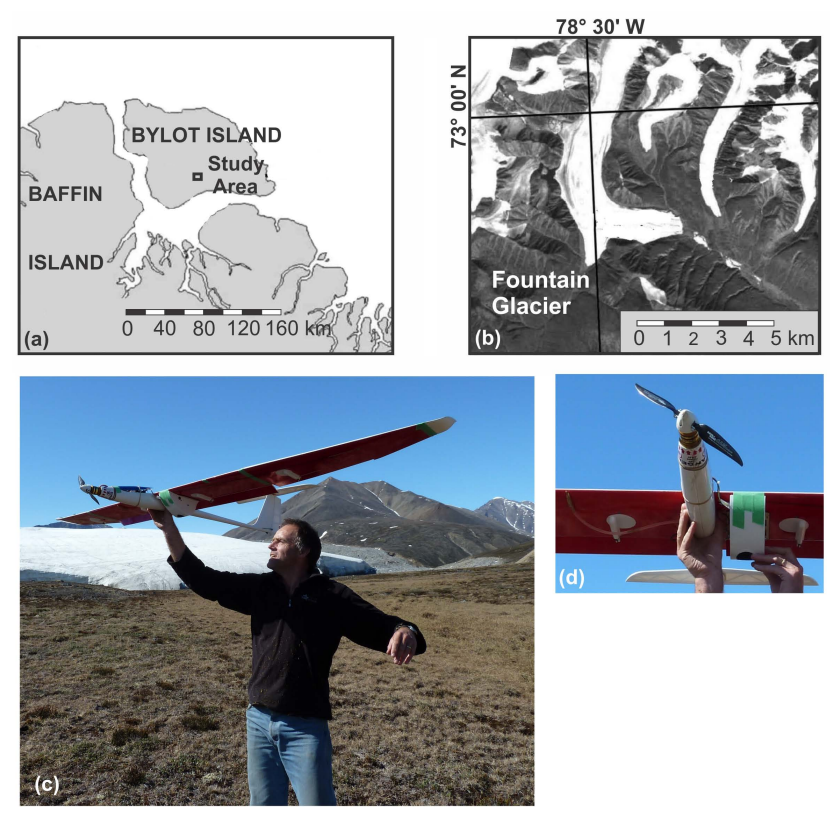

Fig. 1. (a) Location of site on Bylot Island, (b) Landsat 7 image of Fountain Glacier, (c) carrying out pre-flight checks for the Outlander UAV, (d) close-up of propeller assembly showing the location of the camera pod.

Lumix LX3 camera, with a retractable lens assembly. While a camera with a fixed focal length would have been preferred, the payload was limited to approximately $0.5 \mathrm{~kg}$, thus limiting the camera choice. The LX3 has a sensor array size of $8.07 \mathrm{~mm}$ by $5.56 \mathrm{~mm}$, and in the image mode used gave images which were 3648 pixels by 2736 pixels. To keep camera lens parameters consistent with the values established for the existing camera calibration, the zoom was set to the widest possible coverage, giving an effective focal length of approximately $5.1 \mathrm{~mm}$.

A total of 148 images were collected during the survey along 16 north-south oriented flight lines. The forward overlap was set to $65 \%$, with a $65 \%$ overlap between adjacent strips. This level of redundancy ensured there were no gaps in stereo coverage. Flying height was set to $300 \mathrm{~m}$ above the glacier surface, yielding a ground resolution of approximately $0.12 \mathrm{~m}$. To account for the decrease in surface elevation down-glacier the autopilot was programmed to drop the aircraft $12 \mathrm{~m}$ between flight lines. The survey took approximately $30 \mathrm{~min}$, and after landing, the aircraft's log file was downloaded for use in photogrammetric processing.

Prior to the aerial survey, 16 ground control points (GCPs) were surveyed on the glacier and in the adjacent moraine areas, using a Trimble dual-frequency GPS receiver, operating in real time kinematic (RTK) mode. The assumed accuracy of these points was $5 \mathrm{~cm}$ in $X$ and $Y$, and $5 \mathrm{~cm}$ in $Z$, reflecting uncertainty associated with identification of target centres. Targets on the glacier were $0.3 \mathrm{~m}$ diameter red circles, with larger $0.6 \mathrm{~m}$ targets being used in the darker moraine areas 
to improve contrast. GCPs were surveyed the day before the aerial survey.

Aerial triangulation (AT) was carried out using the MatchAT module of Inpho, which is a full-featured digital photogrammetry package produced by Trimble. The AT process uses conjugate points identified across multiple overlapping images in order to carry out a bundle-block adjustment, allowing photo centre positions and camera rotations to be reconstructed from a small number of GCPs. Images from every second strip were used to cover the whole area, with fillin images from the remaining strips being used to enhance stereo coverage for the steeply sloping valley sides. The AT process was carried out three times. The first time, all the GCPs were used to give the best overall adjustment. MatchAT was then rerun with the self-calibration option selected in order to minimize residuals. This process does not make changes to the camera focal length, but rather generates a correction grid for the camera which optimally models lens distortion across the entire block of photos. The triangulation was then re-initialised, and the process repeated, with an evenly distributed subset of nine GCPs being excluded from the triangulation for use as check points. The distribution of GCPs and check points used is shown in Fig. 2a.

Following the AT process, a $1 \mathrm{~m}$ resolution DEM was generated for the entire survey area using the Match-T DSM module of Inpho. This package uses an automated point matching technique to generate a dense surface model of the survey area. Because the ice surface was generally snow free, the images were strongly textured, providing optimal conditions for point matching and DEM creation.

Direct measurements of the glacier surface elevation were made in 3-D from the source imagery, using Inpho's DT Master editing suite. These elevations were typically found to be within $0.5 \mathrm{~m}$ of the DEM elevation. However, elevation discrepancies of several metres were noted in steeply sloping marginal areas, and in the vicinity of the main supraglacial stream. These areas were manually edited by adding a series of break lines and form lines. The elevation points were then re-interpolated to better reflect the surface in these regions. This edited surface model was then used to generate a $0.1 \mathrm{~m}$ resolution orthomosaic image, which is shown in Fig. 2a.

\subsection{Piloted helicopter survey}

A follow-up survey was carried out using a piloted helicopter on 2 July 2011. For this survey a Panasonic Lumix GF1 camera was fixed to the landing gear of a Bell 206L helicopter. This camera had a sensor size of $17.3 \mathrm{~mm}$ by $13 \mathrm{~mm}$, with an image size of 4000 by 3000 pixels, and was used with a fixed $14 \mathrm{~mm}$ lens. Flight lines were flown across the glacier in a north-south pattern at approximately $400 \mathrm{~m}$ above the glacier surface, giving a ground resolution of approximately $0.12 \mathrm{~m}$. The camera was triggered manually, approximately every $4 \mathrm{~s}$. In total, 160 images were acquired, giving full stereo coverage of the area flown the previous year.

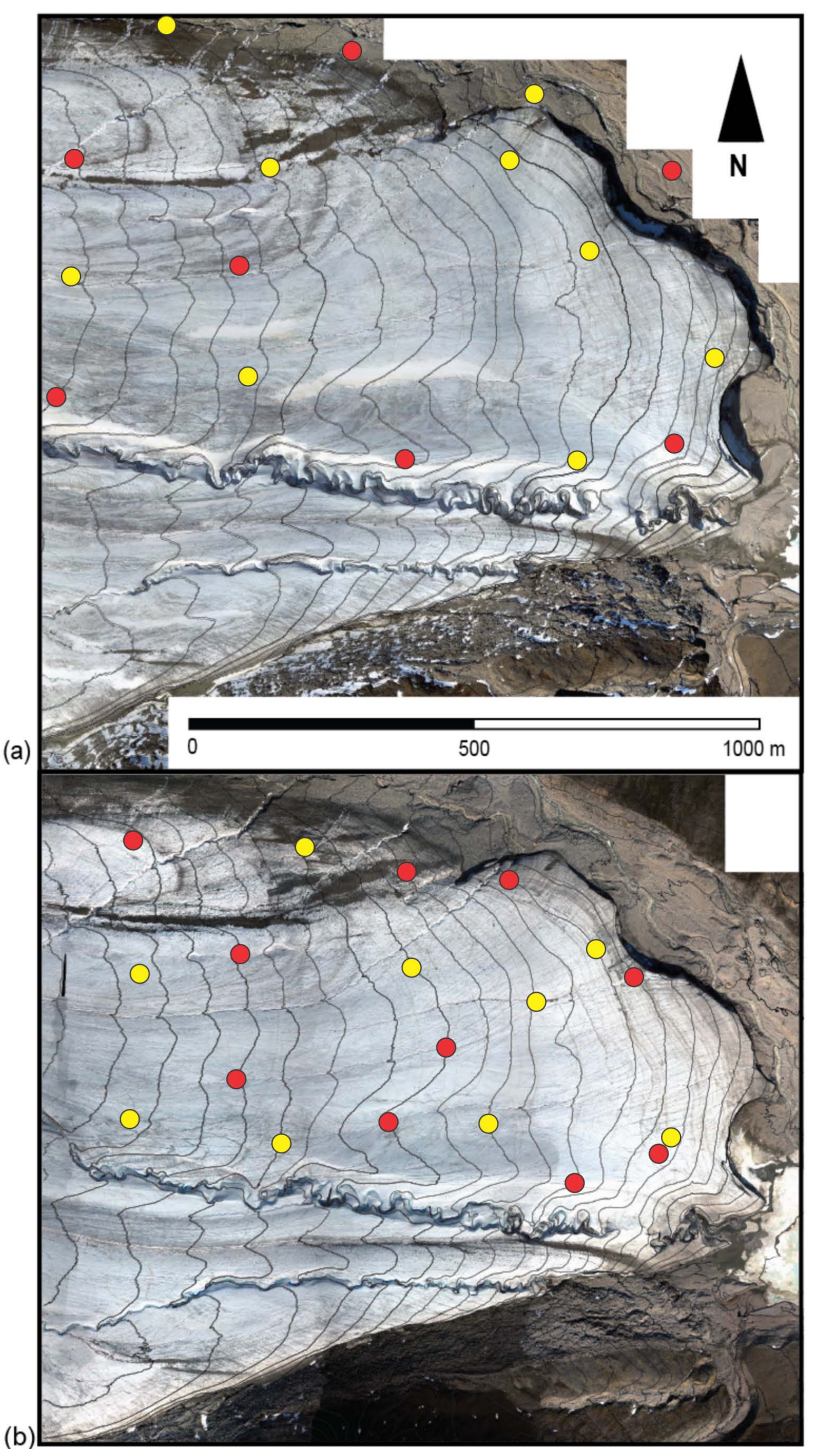

Fig. 2. Orthomosaic images of the glacier terminus from (a) 2010 (UAV) and (b) 2011 (piloted helicopter). Contour interval is $10 \mathrm{~m}$. Red dots indicate GCPs, while yellow dots show check points used for each survey.

Since no $\log$ file was available from the helicopter survey, initial image centre positions were estimated using the UAV orthomosaic image from 2010, with a nominal flying height of $400 \mathrm{~m}$ above the glacier surface. The camera was assumed to be pointing straight down and oriented parallel to the flight lines. Due to time constraints, it was not possible to survey target positions prior to the image acquisition. Instead, 20 GCPs were gathered after the aerial survey, using natural features on the glacier surface which could be easily identified on the images. The GCPs had the same assumed accuracies as for the previous year. However, the uncertainty associated with the identification of these points was higher, 
since the exact identification of points on each image was more difficult.

The images were processed in the same way as those from the previous year. In this case, the camera calibration did not need to be refined, since a good calibration already existed. Nine well-distributed GCPs were used as independent check points to estimate overall accuracy, with the remaining points used for the AT process. After the adjustment a $1 \mathrm{~m}$ resolution DEM was produced. This was manually edited to improve the fit in marginal areas, and in the vicinity of the supraglacial stream. The height model was then used to generate a $0.1 \mathrm{~m}$ orthomosaic image (Fig. 2b).

\subsection{Feature tracking}

Feature tracking from the two orthomosaics was used to determine surface motion between 2010 and 2011. We first tried an automated feature tracking approach using COSICorr software (e.g. Herman et al., 2011); however, because after initial testing there were large areas that had relatively poor correlation, we abandoned this method. We then applied direct visual comparison between prominent features on the two images, such as groups of rocks and vertical cracks in the glacier surface. In total approximately 400 points were identified and $10 \mathrm{~m}$ resolution rasters of magnitude and direction were derived from these points by linear interpolation.

\section{Results}

Figure 3a shows a comparison of the glacier terminus position in 2010 and 2011. In general, changes were too small to be measurable. However, region A on the northern side of the terminus showed significant loss of ice, which was most likely caused by undercutting from the adjacent marginal stream. The change at B is believed to be due to the loss of a major block of ice from the northern calving face. The changes shown at $\mathrm{C}$ reflect erosion caused by the main supraglacial stream, as it flowed from the glacier onto the proglacial floodplain.

Figure $3 \mathrm{~b}$ shows the difference in ice surface elevation between 2010 and 2011. The changes do not account for differences in the onset and relative intensity of the summer ablation seasons, which could potentially have a significant effect on the measured ice loss over a single year. It can be seen that while there are significant local variations, the majority of the surface melting occurred on the northern margins of the glacier.

In general, the differences in surface elevation were between $1.5 \mathrm{~m}$ and $2.5 \mathrm{~m}$ on the northern side of the glacier, with differences of between $1.0 \mathrm{~m}$ and $1.5 \mathrm{~m}$ closer to the centre. Ice-free areas adjacent to the glacier generally showed little change. However, thickening in excess of $1 \mathrm{~m}$ can be seen for the proglacial icing, which is located to the east of the terminus.
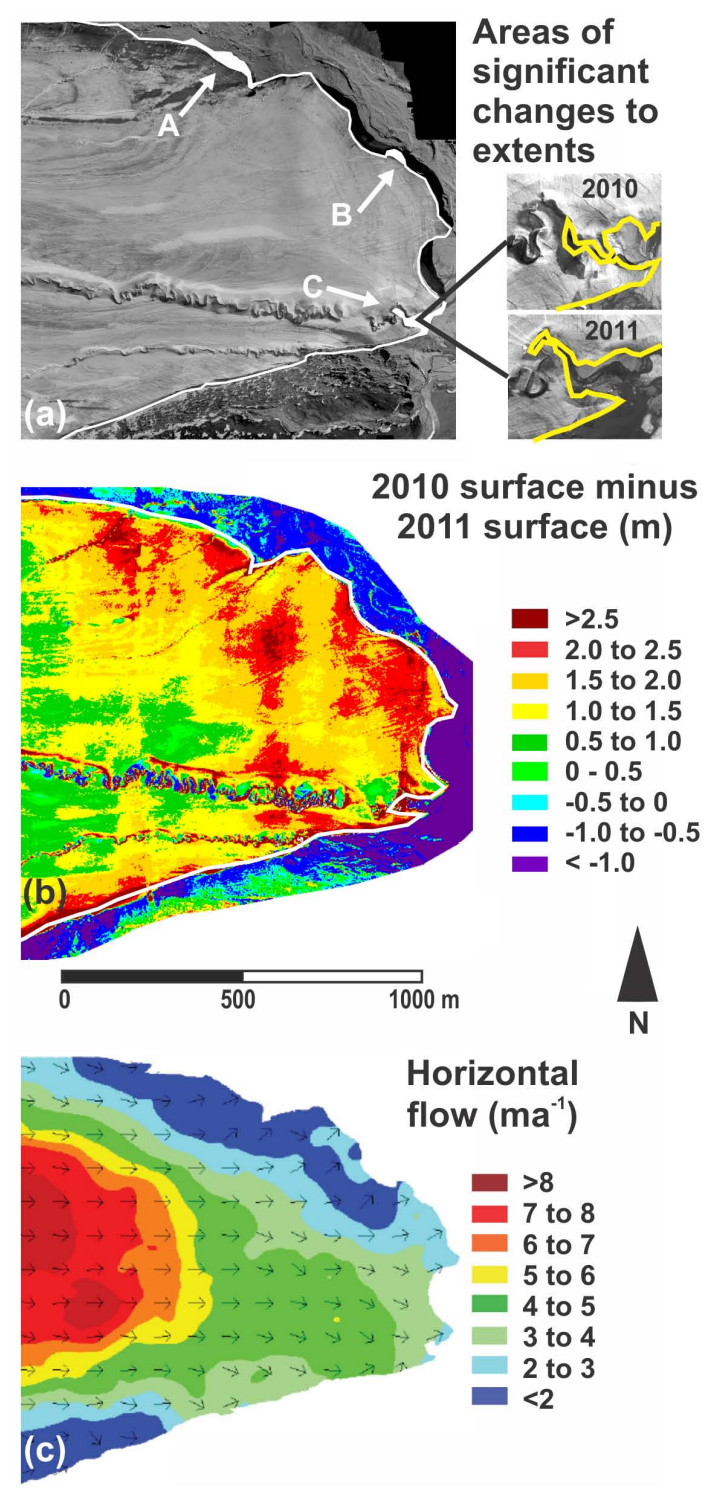

Fig. 3. (a) Changes in glacier margins from 2010 to 2011 (inset shows detail of changes around the exit point of the supraglacial stream). Areas where significant changes have occurred are shown in white and denoted by A, B and C; (b) change in ice thickness measured from 1 July 2010 to 2 July 2011. Increases in thickness to the east of the terminus reflect changes to the proglacial icing; (c) horizontal flow speed and flow direction between 1 July 2010 and 2 July 2011.

\subsection{Ice flow}

From the average annual ice flow map in Fig. $3 \mathrm{c}$ it is apparent that flow rates ranged from near zero for marginal regions on the northern and southern sides of the glacier, up to $8 \mathrm{ma}^{-1}$ in the centre, about $1300 \mathrm{~m}$ from the terminus. The velocities shown in Fig. 3c are horizontal $(X Y)$, rather than surfaceparallel $(X Y Z$ ), because the surface thinning (Fig. 3b) is of the same order of magnitude as the flow speed and could 
introduce errors in surface-parallel measurements of downglacier velocity. Displacements derived from manual feature tracking were compared with displacements for the same area obtained from SAR interferometry (Whitehead et al., 2010), and were generally found to agree to within $0.5 \mathrm{ma}^{-1}$. The direction of ice flow in Fig. 3c shows that overall motion is down-glacier with some deflection towards the margins near the terminus.

\subsection{Accuracy estimates}

The accuracy of the orthomosaics and DEMs were assessed for each survey by converting half of the GCPs to check points. These points were distributed as widely as possible over the glacier surface. For 2010, the RMS error of the image coordinates was $2.3 \mu \mathrm{m}$ in both $x$ and $y$, the GCPs used in the block adjustment process had RMS errors of $0.04 \mathrm{~m}$ in both $X$ and $Y$, and $0.04 \mathrm{~m}$ in $Z$, whereas the check points used had RMS errors of $0.18 \mathrm{~m}, 0.21 \mathrm{~m}$, and $0.42 \mathrm{~m}$ in $X, Y$, and $Z$, respectively. For 2011, the RMS error of the image coordinates was $2.4 \mu \mathrm{m}$ in $x$ and $2.6 \mu \mathrm{m}$ in $y$, the GCPs used in the block adjustment process had RMS errors of $0.01 \mathrm{~m}$ in both $X$ and $Y$, and $0.004 \mathrm{~m}$ in $Z$, with RMS errors for the check points of $0.63 \mathrm{~m}, 0.52 \mathrm{~m}$, and $0.19 \mathrm{~m}$ in $X, Y$, and $Z$. The higher $X$ and $Y$ errors for the 2011 data are likely due to the fact that natural features, rather than targets, that were used as GCPs. To test the influence of the selected points, the triangulations for both years were repeated using different combinations of GCPs and check points. For both years, the RMS errors were found to be similar to those from the original triangulations, suggesting that individual points were not unduly influencing the results of the triangulation and block adjustment process.

The elevations of a further six independent targets on the glacier surface were measured on 3 July 2010 and on 2 July 2011 by GPS. These targets were part of a related study, using ground-based photogrammetry (Whitehead et al., 2010). The difference in GPS elevations was calculated for each point, and this was then corrected for the vertical component of down-glacier motion, to give the change in surface elevation had the target remained stationary. The mean elevation difference derived from the two DEMs was $2.36 \mathrm{~m}$, whereas the mean elevation difference derived from GPS measurements was 1.94. The RMS error over all six points was $0.30 \mathrm{~m}$, suggesting that the difference between the two DEMs may slightly overestimate the amount of surface melt that occurred over the one year period.

To give an estimate of the accuracy of feature tracking, 20 evenly distributed points were identified in both orthomosaics in the moraine areas around the edge of the glacier. These measurements gave RMS errors of $0.99 \mathrm{~m}$ and $1.24 \mathrm{~m}$ in $X$ and $Y$, respectively. While this level of accuracy is comparatively poor, it should be noted that all points were located well outside of the controlled area used to generate the DEMs and orthomosaics, and were mostly situated on the steeply sloping valley sides. It is therefore likely that the points on the glacier surface would show lower RMS errors. From the previous section, the overall horizontal RMS error derived from check points on the glacier was $0.27 \mathrm{~m}$ in 2010 , and the corresponding error for 2011 was $0.81 \mathrm{~m}$. In a worst-case scenario, these errors would act in opposite directions, giving a potential maximum horizontal error for feature tracking of $1.08 \mathrm{~m}$. This corresponds to a $35 \%$ error for slow-moving parts of the glacier at the margins. For fastermoving parts the estimated error drops to $12 \%$. We surmise that these percentages would decrease considerably if physical targets had been used in 2011. These figures also suggest that registration errors between the two $1 \mathrm{~m}$ resolution DEMs are unlikely to exceed one pixel on the glacier surface.

\section{Discussion and conclusions}

This study shows how low-cost aerial surveying from UAVs and manned helicopters can be used to obtain high-resolution and timely remote sensing data. By processing imagery obtained from such surveys using digital photogrammetric software it is possible to obtain high-resolution DEMs and orthomosaic images. Repeat surveys allow ongoing processes such as ice flow, marginal recession, ablation, and seasonal drainage development to be effectively monitored on an ongoing basis. Limitations imposed by battery life, and the challenges of operating beyond line of sight, do however currently impose limitations on the size of areas which can be covered by UAV surveys. For example, a survey of the entire $16 \mathrm{~km}$ length of Fountain Glacier would require multiple flights and would necessitate physical access to the upper glacier, both for control survey and for the purposes of takeoff and landing.

The accuracy estimation should be viewed as provisional because the number of check points for the orthoimages and DEMs was small. Nevertheless, in a recent paper with a much larger number of check points we showed that the vertical RMS error of a photogrammetrically derived DEM, based on UAV imagery, can be equivalent to airborne LiDAR (Hugenholtz et al., 2013). Typical estimates of vertical RMS errors from airborne LiDAR data used in glaciological applications are below $0.2 \mathrm{~m}$ (e.g. Arnold et al., 2006; Hopkinson et al., 2009; Pope et al., 2013), which is not drastically different from the preliminary estimates shown here. Planimetric accuracies reported in the current study are also similar to those reported by Arnold et al. (2006), and Hopkinson et al. (2009), who both estimated $X Y$ accuracies as being between $0.3 \mathrm{~m}$ and $0.4 \mathrm{~m}$. Furthermore, use of a metric camera might reduce some of the errors, and given the growing availability and shrinking size of these cameras, this is a logical next step for UAV payloads.

This project also shows the versatility of digital smallscale aerial photogrammetry, using off-the-shelf cameras. Such an approach is essentially platform independent, and 
it is possible to acquire usable imagery from a variety of manned and unmanned aerial platforms. UAVs are particularly useful in the context of remote sensing because they are autonomous, relatively low cost, compact, and offer flexibility for acquiring on-demand imagery. Furthermore, the number of specialized payloads available for small UAVs is growing rapidly, including SAR, LiDAR and hyperspectral (cf. Hugenholtz et al., 2012). Overall, the results from this case study provide strong support to continued testing and application of UAVs in glaciological mapping and measurement.

Acknowledgements. The authors acknowledge financial and inkind contributions from the Arctic Institute of North America, the Polar Continental Shelf Project, Accuas Services Inc., and Parks Canada. We would also like to thank the two anonymous reviewers for their constructive comments, which helped to improve the quality of the final paper.

Edited by: T. Bolch

\section{References}

Arnold, N. S., Rees, W. G., Devereux, B. J. and Amable, G. S.: Evaluating the potential of high resolution airborne LiDAR data in glaciology, Int. J. Remote Sens., 27, 1233-1251, 2006.

d'Oleire-Oltmanns, S., Marzolff, I., Peter, K. D., and Ries, J. B.: Unmanned Aerial Vehicle (UAV) for monitoring soil erosion in Morocco, Remote Sens., 4, 3390-3416, 2012.

Fonstad, M. A., Dietrich, J. T., Courville, B. C., Jensen, J. L., and Carbonneau, P. E.: Topographic structure from motion: a new development in photogrammetric measurement, Earth Surface Processes and Landforms, 38, 421-430, 2013.

Herman, F., Anderson, B., and Leprince, S. B.: Mountain glacier velocity variation during a retreat/advance cycle quantified using sub-pixel analysis of ASTER images, J. Glaciol., 57, 197-207, 2011.

Hopkinson, C., Hayashi, M., and Peddle, D.: Comparing alpine watershed attributes from LiDAR, Photogrammetric, and Contourbased Digital Elevation Models, Hydrol. Process., 23, 451-463, 2009.
Hugenholtz, C. H., Moorman, B. J., Riddell, K., and Whitehead, K.: Small unmanned aircraft systems for remote sensing and earth science research, Eos, Transactions American Geophysical Union, 93, 236-236, 2012.

Hugenholtz, C. H., Whitehead, K., Barchyn, T. E., Brown, O. W., Moorman, B. J., LeClair, A., Hamilton, T., and Riddell, K.: Geomorphological mapping with a small unmanned aircraft system (sUAS): feature detection and accuracy assessment of a photogrammetrically-derived digital terrain model, Geomorphology, 194, 16-24, 2013.

James, M. R. and Robson, S.: Straightforward reconstruction of 3D surfaces and topography with a camera: Accuracy and geoscience application, J. Geophys. Res.: Earth Surface (20032012), 117, F03017, doi:10.1029/2011JF002289, 2012.

Moorman, B.: Glacier-permafrost hydrology interactions, Bylot Island, Canada, Proceedings 8th International Permafrost Conference, Zurich, Switzerland, edited by: Phillips, M., Springman, S. M., and Arenson, L., 783-788, A.A. Balkema Publishers, 2003.

Pope, A., Willis, I. C., Rees, W. G., Arnold, N. S., and Palsson, F.: Combining airborne lidar and Landsat ETM+ data with photoclinometry to produce a digital elevation model for Langjokull, Iceland, Int. J. Remote Sens., 34, 1005-1025, 2013.

Quincey, D. J. and Luckman, A.: Progress in satellite remote sensing of ice sheets, Prog. Phys. Geogr., 33, 547-567, 2009.

Wainstein, P., Moorman, B., and Whitehead, K.: Importance of glacier - permafrost interactions in the preservation of a proglacial icing: Fountain Glacier, Bylot Island, Canada, Proceedings Ninth International Conference on Permafrost, Fairbanks, Alaska, edited by: Kane, D. L. and Hinkel, K. M., 18811886, 2008.

Wainstein, P., Moorman, B., and Whitehead, K.: Hydro-physical conditions of an Arctic proglacial valley, Bylot Island, Proceedings 63rd Canadian Geotechnical Conference \& 6th Canadian Permafrost Conference, Calgary, Alberta, 1525-1532, 2010.

Westoby, M. J., Brasington, J., Glasser, N. F., Hambrey, M. J., and Reynolds, J. M.: Structure-from-Motion photogrammetry: A low-cost, effective tool for geoscience applications, Geomorphology, 179, 300-314, 2012.

Whitehead, K., Moorman, B., and Wainstein, P.: The Use of Ground-Based Photogrammetry and SAR Interferometry to Characterize the Surface Motion of an Arctic Glacier, Proceedings 63rd Canadian Geotechnical Conference \& 6th Canadian Permafrost Conference, Calgary, Alberta, 1323-1328, 2010. 